\title{
BG20
}

\section{Visualizing Borehole Images in a Slabbed-Core} Format

\author{
A. Kumar* (Schlumberger), R. Laronga (Schlumberger), J. Kherroubi \\ (Schlumberger), F. Bringer (Schlumberger), G. Kear (Schlumberger) \& J. \\ Herrera (Schlumberger)
}

\section{SUMMARY}

A core slab provides geologists a continuous view of the rock in two-dimensions, exactly as one would see in a road-cut or how one looks at any picture. Another very effective source for detailed geological interpretation is the borehole image. Borehole images provide a continuous image of the sub-surface geology as seen in the borehole wall. The images are presented as an unwrapped cylinder of the borehole wall. However, in this view, planes, such as bedding planes, fractures, faults, etc., get displayed as sinusoids rather than as straight lines as seen in core slabs. In this paper, the standard view of presenting borehole images is discussed as a "Sinusoidal view". If a geologist can be provided with borehole images where planes are seen as straight lines, as in a slabbed core, the geologist is able to extract more information from the image and do superior geological interpretations.

This paper discusses an advanced new mode of displaying borehole images - in true two-dimensions in a slabbed-core-like format. The paper also presents cases from different geological settings demonstrating the value of the gain in geological interpretation using the new image visualization format. 


\section{Introduction}

A prime reason millions of dollars are spent taking a core is to get a core slab for detailed geological interpretation. A core slab provides geologists a continuous view of the rock in two-dimensions, exactly as one would see in a road-cut or how one looks at any picture. A two-dimensional view is the perfect way to do geological interpretation from a core. Another very effective source for detailed geological interpretation is the borehole image. Borehole images provide a continuous image of the sub-surface geology as seen in the borehole wall. The images are presented as an unwrapped cylinder of the borehole wall. The unwrapping process allows a three dimensional surface to be displayed and worked on as a pseudo-two dimensional surface. However, in this view, planes, such as bedding planes, fractures, faults, etc., get displayed as sinusoids rather than as straight lines as seen in core slabs. In this paper, the standard view of presenting borehole images is discussed as a "Sinusoidal view". Conducting interpretation visually based on these "sinusoidal" images involves lots of training and experience, and many industry geologists are not able to comprehend the details in these "sinusoidal view" borehole images even though they may be excellent geologists. If a geologist can be provided with borehole images where planes are seen as straight lines, as in a slabbed core, the geologist is able to extract more information from the image and do superior geological interpretations.

This paper discusses an advanced new mode of displaying borehole images - in true two-dimensions in a slabbed-core-like format. The paper also presents cases from different geological settings demonstrating the value of the gain in geological interpretation using the new image visualization format.

\section{Theory and Background}

An important question to answer is how to get a slabbed-core view of the borehole from the borehole image. A borehole is created when the rock material there is drilled out. In a typical imaging operation, a borehole imager acquires the measurements from the borehole wall and the borehole image is made out of the data acquired at the borehole wall. Dips are then picked from the borehole image. The dips represent planes that intersect the borehole.

Once these planes have been defined, they can be used as the skeleton framework to create a crosssection - a slabbed-core view - of the bedding and other features observed in the image. At that point, image details can be mathematically projected onto the plane of slabbing with guidance from the planes. Furthermore, once the planes have been defined, they make it possible to view this slabbed-core view in any direction. With the conclusion of the procedure, the borehole image is presented in a true two-dimensional (true 2-D) slabbed-core format. Figure 1 is a presentation of an oil base mud borehole image (Laronga et al., 2013) displaying thinly bedded strata in a slabbed-core format as well as other standard and enhanced formats. The first column shows the slabbed-core format. It should also be noted that whereas most slabbed cores are equal to or less than 4 inches $(\sim 10$ $\mathrm{cm})$ wide, the borehole image slabbed-core views have the width of the hole diameter, thus allowing better visualization of the geological features and heterogeneities.

Of all the possible ways to generate true 2-D borehole images, two are discussed here. One mode is to generate the images in a slab direction chosen by the user. Another way is to use an automatic mode where the software chooses the slab direction based on the apparent dip azimuths - picking a slabbing direction perpendicular to apparent dip azimuth in order to display maximum dip. The software is also able to respect abrupt changes of dip across discontinuity planes - such as unconformities or faults. Here, the automatic mode recognizes that the slabbing angle needs to be changed abruptly at the discontinuity rather than smoothly, thus always accurately providing the view that displays maximum dip. 


\section{Applications of Slabbed-Core Format Borehole images}

In addition to the most essential of applications to the slabbed-core images, i.e., visualization in true two-dimensional format, advanced workflows can improve visualization even beyond what is possible with a real core slab. In a deviated well or in a region of very high structural dip, the apparent dips of features observed in the core are highly exaggerated and can be difficult to interpret. This situation is easily addressed with a borehole image in true 2-D format. The true 2-D image can be flattened on structural dip and displayed on an index of True Stratigraphic Thickness. At that point any remaining dip is the real depositional dip, and can be used for stratigraphic interpretation. This becomes the equivalent of having taken a core vertically through an undisturbed stratigraphic column.

Bounding the true 2-D borehole image by a high resolution resistivity curve allows the creation of a virtual stratigraphic column, allowing an outcrop type visualization and more realistic interpretation.

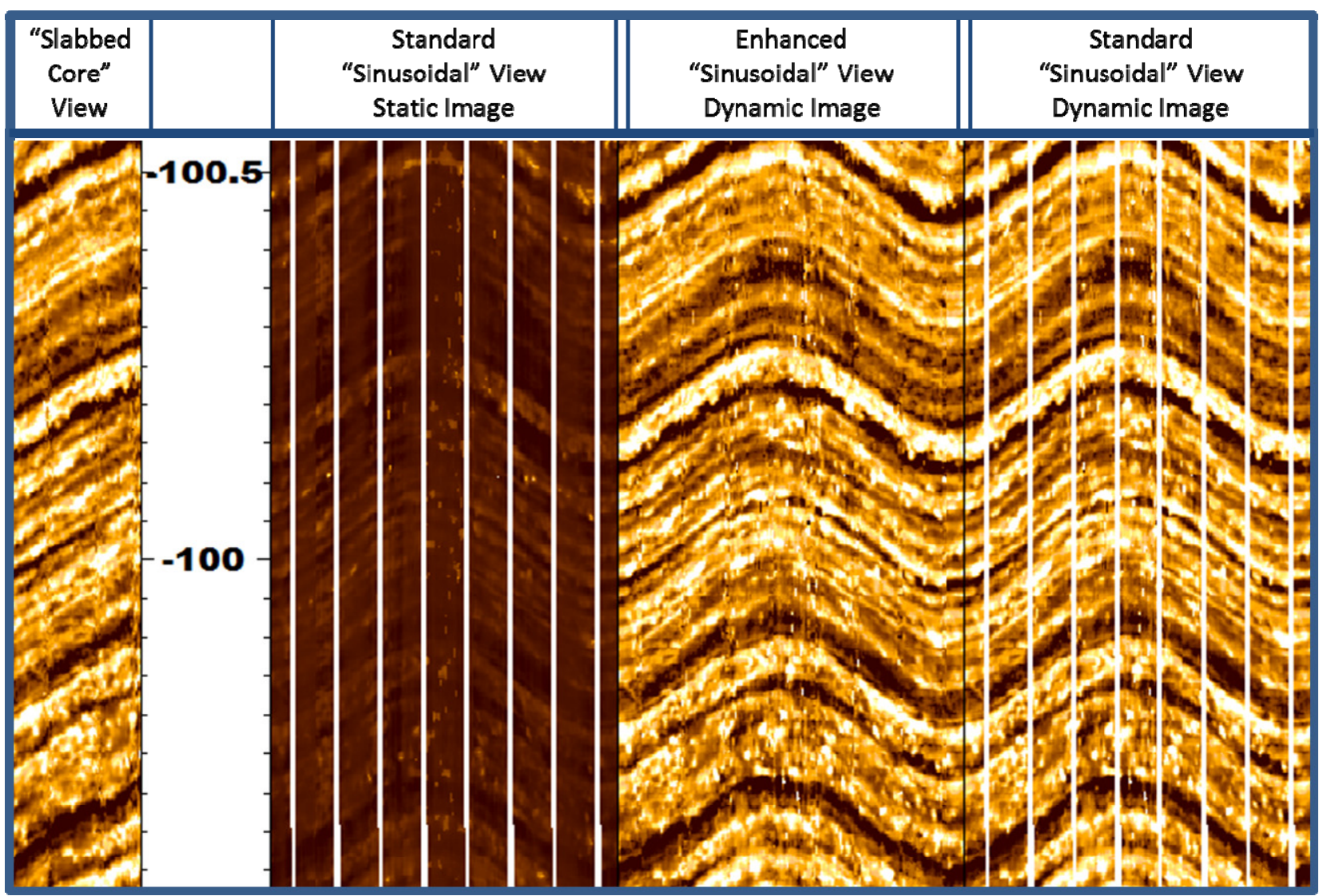

Figure 1 Presentation of an oil base mud borehole image displaying thinly bedded strata in a slabbed-core format as well as other standard and enhanced formats.

\section{Summary and Conclusions}

One reason a whole core acquired in a borehole is to get a core slab for detailed geological interpretation. A core slab provides a geologist a continuous view of the rock in two-dimensions. Borehole images are also used to provide a continuous image of the sub-surface geology as seen in the borehole. Borehole images are presented as an unwrapped cylinder of the borehole wall, where three dimensional planes are displayed as sinusoids rather than as straight lines seen in core slabs. Interpreting these "sinusoidal" images can be challenging to the geologist not specifically trained in borehole image interpretation. 
This paper presents an innovative new mode of displaying borehole images - in true two-dimensions in a slabbed-core-like format. The paper discusses the method of generating such images and also demonstrates the value of the gain in geological interpretation using the new image visualization format. Now, geologists trained in standard interpretation techniques are able to apply standard geological principles for interpretation on a two-dimension surface rather than trying to find a way to do that on "sinusoidal" images.

\section{References}

Laronga, R., Kear, G.R., Kumar, A., Vessereau, P., Bloemenkamp, R. and Zhang, T. [2013] A New Tool for High-Resolution Sedimentological Imaging of Deepwater Clastic Reservoirs. American Association of Petroleum Geologists International Conference and Exhibition, Cartagena. 